\title{
Yağlı Isıl İşlem Görmüş Sarıçam Odununda Koruyucu Katmanların Yapışma ve Sertlik Özellikleri
}

\author{
*Hacı İsmail KESİK ${ }^{1}$ Hasan VURDU ${ }^{1}$, Kubulay ÇAĞATAY², Osman Emre ÖZKAN', Mustafa \\ ÖNCEL ${ }^{1}$ \\ ${ }^{1}$ Orman Endüstri Mühendisliği Bölümü, Orman Fakültesi, Kastamonu Üniversitesi, Kastamonu. \\ ${ }^{2}$ İncirli Mesleki ve Teknik Anadolu Lisesi, Mobilya ve İç Mekân Tasarım Alanı, Ankara. \\ *Sorumlu yazar: hismailkesik@kastamonu.edu.tr
}

Geliş Tarihi: 09.04.2015

\begin{abstract}
Özet
Ahşap sahip olduğu bazı avantajları sayesinde birçok kullanım yerinde tercih edilen önemli bir malzemedir. Ancak, biyotik ve abiyotik faktörlerin zaman içerisindeki etkisiyle ahşapta bazı bozulmalar görülmektedir. $\mathrm{Bu}$ sebeple, ahşabın mantar, böcek ve diğer iklim koşullarının etkilerinden dolayı korunmas1 gerekmektedir. Örneğin, koruma yöntemlerinden birisi olan 1sıl işlem ahşabın bazı özelliklerini olumlu yönde artırmaktadır. Özellikle, yağlı ısıl işlemin ahşabın boyutsal kararlılığı ve renk kararlılığını iyileştirdiği görülmektedir. Bu sayede ahşap, bahçe mobilyalarında ya da dış cephe kaplamalarında kullanılabilmektedir.

Bu çalışmada, bezir yağı ile ısıl işlem görmüş sarıçam (Pinus sylvestris L.) odunundan hazırlanan deney numunelerine, su bazlı vernik ve su bazlı boya tatbik edilerek, yapışma ve sertlik performansları belirlenmiştir. Araştırma sonuçlarına göre, bezir yağı ile ısıl işlem gören sarıçam odunlarında, vernik katmanı sertlik değerleri (38), boya katmanı sertlik değerlerinden (25.6) yüksek çıkmıştır.

Anahtar Kelimeler: Yağlı 1sıl işlem, Su bazlı vernik, Su bazlı boya, Yapışma direnci, Sertlik
\end{abstract}

\section{Hardness and Adhesion Characteristics of Protective Layer on Oil Heat Treated Scots Pine Wood}

\begin{abstract}
Wood is a preferred important material due to having many advantages for many uses. However, wood is degraded by time under the effects of biotic and abiotic factors. Therefore, wood should be protected from fungi, insects and other climate factors. Among these, heat treatment methods increase the durability of wood properties. Especially, oil heat treatment improves the dimensional stability and color stability in a positive direction. Thus, wood can be used for garden furniture or siding.

In this study, water based varnish and paint were applied on oil heat treated scots pine (Pinus sylvestris L.) wood. Effects of oil heat treatment on adhesion strength and hardness of varnish and paint films were determined. Results showed that hardness of varnish layers (38) on oil heat treated scots pine wood is higher than paint layers (25.6).
\end{abstract}

Keywords: Oil heat treatment, Water based varnish, Paint, Adhesion strength, Hardness

\section{Giriş}

Ahşap sahip olduğu bazı avantajları sayesinde birçok kullanım yerinde tercih edilmektedir. Ancak, ahşabı̀n higroskopik olması, mantar ve böcek saldırıları sonucu bozulması, istenilmeyen özellikleri arasında yer almaktadır. Ahşabın istenilmeyen özelliklerini en aza indirmek için klasik bir yöntem olan emprenye, uzun zamandan beri tercih edilmektedir. Emprenye işleminde kullanılan zehirli kimyasallar üzerinde oluşturulan çevresel baskılar ve bazı emprenye kimyasallarına gelen kisitlamalar, odunun korunmasinda farklı koruyucu yöntem ve arayışlarını gerekli kılmıştır (Homan ve ark., 2000; Hill, 2006).

Odun modifikasyonu yöntemleri, odunun rutubet alıp vermesi, boyutsal değişimi gibi diğer bazı kusurların doğaya duyarlı şekilde iyileştirilmesi olarak tanımlanmıştır (Homan ve ark., 2000; Hill, 2006). Odun modifikasyonu yöntemleri; kimyasal, fiziksel, termal ve enzimatik olmak üzere dört gruba ayrılmaktadır. Kimyasal modifikasyonda, emprenye yöntemlerinden farklı olarak kullanılan kimyasal maddelerin oduna bağlanması ile daha kalıcı bir şekilde koruma sağlanmaktadır. Fiziksel modifikasyonda, kimyasal bağ söz konusu olmayip kullanilan maddeler odun hücrelerinde yer alan boşluklara yerleşerek koruma sağlanmaktadır. Enzimatik reaksiyonda, laktaz gibi bazı enzimler kullanilarak odun modifiye edilmektedir. Termal modifikasyonda ise, odun belirli bir atmosfer veya ortam içerisinde sıcaklığa 
maruz birakılarak odun modifikasyonu gerçekleştirilmektedir (Suttie ve Thompson, 2001). Odunun asetillendirilmesi ve termal modifikasyon (1sıl işlem) yöntemleri günümüzde ticari olarak uygulanmaya başlamıştır (Tomak ve Yıldız, 2010). Asetillendirme sonucu hücre çeperlerinde yer alan hidroksil gruplar, hidrofobik asetil gruplarına dönüşür. Böylece odunun su almasindan sorumlu olan gruplar, yapilan modifikasyon sonucu bu işlevini büyük oranda kaybederler (Homan ve ark., 2000).

Termal modifikasyon yöntemi ile odunun boyutsal çalışmasının azaldığı ve çürümeye karş1 direncinin arttığ 1 uzun zamandan beri bilinmektedir (Hill, 2006). Bundan dolay1, günümüzde endüstriyel kullanım yeri ve ağaç türlerine göre termal modifikasyon, farkl1 yöntemlerle uygulanmaktadır. Bu yöntemler arasında olan yağlı 1sıl işlem 2000'li yıllarda bahçe mobilyaları için Almanya'da geliştirilerek uygulanmaya başlamıştır. $\mathrm{Bu}$ yöntem, kolza yağı, bezir yağı veya ayçiçek yağı gibi bitkisel yağların kapalı bir tank içerisinde belirlenen bir sıcaklık ve belirli sürede uygulanması işlemidir.

Temiz ve ark. (2006), $240{ }^{\circ} \mathrm{C}$ 'de 1 sil işlemle muamele edilmiş odunları, hızlandırılmış (UV) yaşlandırma testine tabi tutmuş ve 1sıl işlem uygulanan odunlarda, kontrol numunelerine göre daha az renk değişikliği olduğunu tespit etmiştir. Ayrıca, yapılan su alma ve çürüklük deneylerinde, 1sıl işlemli odunda olumlu bir performans artışı görülmüştür.

Yıldız ve ark. (2011), 1sıl işlem uygulanmış kızılağaç odunlarına doğal yaşlandırma deneyi uygulamış, isıl işlemli odunların kontrol numunelerine göre daha az ağırlı kaybı verdiğini, 1sıl işlemli numunelerde meydana gelen ağırlık kayıplarındaki azalmaların sıcaklığın artması ile daha da azaldığını tespit etmişlerdir.

Dubey ve ark. (2012), Pinus radiata odunların $160{ }^{\circ} \mathrm{C}$ ile $210{ }^{\circ} \mathrm{C}$ 'ler arasinda bezir yağ 1 ile muamele etmiştir. Odunlarda 1sıl işlemle birlikte homojen ve koyu renge doğru bir geçiş olduğunu, boyutsal kararlılıkta \%60, mantar çürüklüğüne karş1 dayanımda ise \%36 oranında iyileşme olduğunu belirlemiştir.

Özkan (2013), beziryağı ile 2,4 ve 6 saat sürelerle $150{ }^{\circ} \mathrm{C}, 180{ }^{\circ} \mathrm{C}$ ve $200{ }^{\circ} \mathrm{C}$ 'de 1 sil işleme maruz bıraktığı Uludağ göknarı odunlarını, doğal yaşlandırmaya tabi tutmuştur. Bunun sonucunda, $150{ }^{\circ} \mathrm{C}$ 'de 2 saat süre ile uygulanan yağlı 1sıl işlemin, denge rutubeti oranında $\% 49$, su almada $\% 76$, hacimsel şişmede $\% 26$, yaşlandırma renk kararlılığında \%35 oranlarında olumlu yönde artış meydana getirdiğini belirlenmiştir. Ayrıca, mekanik dayanım ve yüzey pürüzlülüğü özellikleri açısından da gelişmelerin olumlu ve uygulanabilir olduğunu tespit etmiştir.

FPInnovations (2008), ssıl işlemli Pinus contorta çamı odunlarına uygulanan su ve solvent bazlı farklı koruyucu katmanların yapışma dirençlerini araştırmıştır. Araştırma sonucunda, solvent bazlı Sikkens Cetol 123 ${ }^{\circledR}$ ve su bazlı SuperNatural ${ }^{\circledR}$ verniklerin performansları olumlu bulunmuş, su bazlı SuperNatural ${ }^{\circledR}$ verniğgin görüntüsünün güzel olması sebebiyle kullanımını tavsiye etmiştir.

Ahşabın bazı olumlu özelliklerini artıran 1sıl işlem ve yağlı isıl işlem yöntemleri endüstriyel olarak uygulanmaktadır. Dolayısıyla, olumlu yönde özellikleri artırılan ahşap malzeme, dış cephe kaplamalarında ve ahşap bahçe mobilyalarında kullanılmaya başlanmıştır. Burada, bezir yağı ile 1sıl işlem görmüş odun yüzeyinde oluşan katman ve değişimlerin, vernik ve boya etkileşim özelliklerinin bilinmesine büyük ihtiyaç duyulmaktadır. Vernik katman sertlik değeri, verniklerin diş etkenlere dayanıklılığını belirleyen en önemli göstergelerden biridir (Atar ve ark. 2003). Bu çalışmada, bezir yağı ile 1 sıl işlem görmüş sarıçam odunlarına uygulanan, su bazlı vernik ve boya katmanlarının yapışma direnci ve sertlik değerlerinin belirlenmesi amaçlanmıştır.

\section{Malzeme ve Yöntem Ağaç malzeme}

$\mathrm{Bu}$ çalışmada, sarıçam (Pinus sylvestris L.) odunu deney materyali olarak seçilmiştir. Deney örnekleri, doğal kurutma şartlarının uygulandığ 1 bir kereste deposundan temin edilmiştir. TS 2470 'e göre, deney numuneleri 1. sınıf ağaç malzemeden, düzgün lifli, budaksı, çatlaksız, renk farkı olmayan, reaksiyon odunu bulunmayan, mantar ve böcek zararına uğramamış, radyal kesilmiş ve diri odun kısımlarından seçilmiştir. 


\section{Koruyucu}

Çalışmada kullanılan sentetik bezir yağı, Yeni Turan A.Ş. firmasından, D70 isimli su bazlı vernik $(\mathrm{SbV})$ ve su bazlı boya $(\mathrm{SbV})$ Kimetsan Ltd. Şti. firmasından temin edilmiştir. Vernik ve boya, akrilik modifiye poliüretan kopolimer özelliktedir.

Çalışmada kullanılan bezir yağının özellikleri Tablo 1'de, vernik ve boyanın özellikleri ise Tablo 2'de verilmiştir.

\section{Yapıştıricı}

TS EN ISO 4624'e göre Bison ${ }^{\mathrm{TM}}$ firmasına ait, çift bileşenli epoksi reçineli bir yapıştırıcı kullanılmıştır. Bu yapıştırıcı, firma önerisi doğrultusunda yüzeylerde $150 \pm 10$ $\mathrm{g} / \mathrm{m}^{2}$ olacak şekilde uygulanmıştır.

Tablo 1. Bezir yağı özellikleri (Anonim, 2015)

\begin{tabular}{|c|c|c|c|c|c|c|c|}
\hline $\begin{array}{l}\text { Koruyucu } \\
\text { Katman }\end{array}$ & Renk & $\begin{array}{c}\text { Yoğunlu } \\
\text { k }\end{array}$ & $\begin{array}{l}\text { Sabunlaşm } \\
\text { a İndisi }\end{array}$ & $\begin{array}{c}\text { Kül } \\
\text { Miktar1 }\end{array}$ & $\begin{array}{c}\text { Kat1 } \\
\text { Madde }\end{array}$ & $\begin{array}{c}\text { Asit } \\
\text { İndisi }\end{array}$ & $\begin{array}{c}\text { Sabunlaşmaya } \\
\text { n Maddeler }\end{array}$ \\
\hline $\begin{array}{c}\text { Sentetik } \\
\text { bezir yağ1 }\end{array}$ & $\begin{array}{l}\text { Sariya } \\
\text { bakan }\end{array}$ & $\begin{array}{c}0.88-0.89 \\
\left(\mathrm{gr} / \mathrm{cm}^{3}\right)\end{array}$ & 188-195 & $\begin{array}{c}\text { En } \\
\text { fazla }\end{array}$ & $\begin{array}{c}\text { En az } \\
\% 60\end{array}$ & $\begin{array}{c}\text { En } \\
\text { fazla } 10\end{array}$ & $\begin{array}{c}\text { En fazla } \\
\% 2\end{array}$ \\
\hline
\end{tabular}

Tablo 2. Vernik ve boyanın özellikleri

\begin{tabular}{ccccccc}
\hline $\begin{array}{c}\text { Koruyucu } \\
\text { Katman }\end{array}$ & PH & $\begin{array}{c}\text { Yoğunluk } \\
\left(\mathrm{g} / \mathrm{cm}^{3}\right)\end{array}$ & $\begin{array}{c}\text { Viskozite }(\mathrm{sn} \\
\text { DINCup/4mm) }\end{array}$ & $\begin{array}{c}\text { Uygulama } \\
\text { Miktar1 } \\
\left(\mathrm{o}^{2} / \mathrm{m}^{2}\right)\end{array}$ & $\begin{array}{c}\text { Tabanca Uç } \\
\text { Açıllığ }(\mathrm{mm})\end{array}$ & $\begin{array}{c}\text { Hava } \\
\text { Basınc1 } \\
(\mathrm{Rarr})\end{array}$ \\
\hline Vernik & $8.5^{*}$ & $1.03^{*}$ & 18 & $70^{*}$ & 0.7 & $1-1.5$ \\
\hline Boya & $8.2^{*}$ & $1.02^{*}$ & 18 & $70^{*}$ & 0.7 & $1-1.5$ \\
\hline *Tespit & & & & & &
\end{tabular}

*Tespit

\section{Deney örneklerinin hazırlanması}

ASTM D-4541 ve TS EN ISO 4624'e göre, 80 adet deney numunesi taslak boyutları 12 x $102 \times 102 \mathrm{~mm}$ olacak șekilde hazırlanmıștır. Hazırlanan numuneler iklimlendirme odasında $\% 65 \pm 5$ bağıl nem ve $20 \pm 2{ }^{\circ} \mathrm{C}^{\prime}$ de değişmez ağırlığa ulaşıncaya kadar bekletildikten sonra, kontak zımpara makinasinda 100 kum zımpara ile 10 x 100 x $100 \mathrm{~mm}$ nihai boyutlara getirilmiştir.

Deney numuneleri TS EN 351-1'e göre $150^{\circ} \mathrm{C}^{\prime}$ de 2 saat süre ile bezir yağı içerisinde 1sıl işleme tabi tutulmuştur. Yağlı 1sıl işlem uygulanan deney numunelerinin yüzeylerindeki fazla yağlar, kurutma kâğıdı kullanılarak silinmiştir. $\mathrm{Bu}$ işlem sonrası numuneler $103 \pm 2{ }^{\circ} \mathrm{C}$ 'deki etüv içerisinde 48 saat boyunca kurumaya bırakılmıștır. Ayrıca, 1sıl işlem öncesi ve sonrası odun numunelerinin ağırlıklarına oranla eşitlik 1'e göre tuttuğu bezir yağı (YT) hesaplanmıştır.

$\mathrm{YT}=\left[\frac{\mathrm{As}-\mathrm{Aö}}{\mathrm{Aö}}\right] \times 100 \%$

As= Isıl işlemli tam kuru ağırlık (gr)

Aö = Isıl işlemsiz tam kuru ağırlık (gr)
Vernikleme ve boyama işlemi, ASTM D3023'e göre yapılmıştır. Verniklerin ve boyaların hazırlanması ve uygulanmasinda üretici firma önerileri dikkate alınmıştır.

Başka dolgu katı uygulanmadan, boya ve verniğin kendisi dolgu amaçlı ve son kat olmak üzere ikişer kat uygulanmıştır. Uygulanan vernik ve boyanın kuruması için katlar arasında 48 saat beklenmiştir. Su çözücülü boya ve verniğin katı madde miktarları göz önünde bulundurularak, her kat için $70 \mathrm{~g} / \mathrm{m}^{2}$ olacak şekilde uygulama yapılmıştır. Daha sonra örnekler, $20 \pm 2{ }^{\circ} \mathrm{C}$ sicaklık ve $\% 65 \pm 5$ bağıl nemdeki iklimlendirme dolabinda denge rutubetine ulaşıncaya kadar bekletilmiştir.

\section{Yapışma tayini}

Yapışma dirençleri ASTM D-4541 ve TS EN ISO 4624'e göre belirlenmiştir. Yapışma direncinin tayininde, koruyucu katmanlarla kaplanarak kondisyonlanan deney numunelerinin yüzeylerine, $20 \mathrm{~mm}$ çapındaki deney silindirleri bir kalıp yardımı ile oda sıcaklığında $\left(20 \pm 2{ }^{\circ} \mathrm{C}\right.$ 'de) yapıştırılmış ve 24 saat süre ile kurumaya terkedilmiştir. Yapışma direncinin ölçümünde kullanılan Shimadzu ${ }^{\circledR}$ deney cihazı ilerleme hızı dakikada $5 \mathrm{~mm}$ olacak şekilde ayarlanmıştır. 
Yapışma direnci eşitlik 2'ye göre $\mathrm{MPa}$ cinsinden hesaplanmıştır $\left(\mathrm{MPa}=1 \mathrm{~N} / \mathrm{mm}^{2}\right)$.

Yapışma direnci $(\mathrm{X})$;

$\mathrm{X}=4 \mathrm{~F} / \pi \cdot \mathrm{d}^{2}$

$\mathrm{F}=$ Kopma anındaki kuvvet (Newton)

$\mathrm{d}=$ Deney silindirinin çap $1(\mathrm{~mm})$

\section{Sertlik tayini}

Vernik ve boya katmanlarının sertlikleri, Köning yöntemi esas alınarak ASTM D4366-95'e göre belirlenmiştir. Ölçme aleti, ölçümlerden önce ve ölçüm aralıklarında, kalibre camı kullanılarak 40 saniyede 100 salınım verecek șekilde kalibre edilmiștir. Prensip olarak, sert yüzeylere sahip numunelerde salınım sayısı fazla, yumuşak yüzeylerde ise daha az miktarda salınım olmaktadir.

\section{Sonuçların değerlendirilmesi}

Verilerin analizinde SPSS 17 program kullanılmıştır. Burada, çoklu faktör basit varyans analizi (ANOVA) ile yağlı 1 s1l işlemin, vernik ve boyanın yüzeye yapışma direnci ve katman sertliği gibi faktörlere olan etkileri belirlenmiştir. Faktör etkilerinin $\alpha=$ 0.05 hata payı ile anlamlı çıktığı durumlarda Duncan testi ile homojen gruplar tespit edilmiştir.

\section{Bulgular}

\section{Emilen yağ miktarı}

Yağlı 1sıl işlem uygulaması sonucu sarıçam odunu numunelerinde yağ tutunum oranı ortalama \%4.22 olarak tespit edilmiştir. Sidorova (2008), farklı ağaç türleri kullanarak $180^{\circ} \mathrm{C}$ 'de $30 \mathrm{dk}$. süre ile yağlı $1 \mathrm{~s} 1 \mathrm{l}$ işlem uygulamıştır. Yağ tutunum oranlarını ladinde \%3.19, çam öz odununda \%1.39, çam diri odununda 3.61 ve titrek kavakta $\% 10.84$ olarak tespit etmiştir. Yağ tutunum oranlarındaki bu farklılıklar, türler arasındaki anatomik, geçirgenlik, öz odunu miktarı (Dubey ve ark., 2011; Bazyar, 2012; Özkan, 2013) ve y1llik halka özelliklerinden kaynaklanmaktadır.

\section{Yüzeye yapışma direnci ve sertlik ölçümü \\ Deney numunelerine ait koruyucu} katmanların yapışma direnci ve sertlik değerleri Tablo 3'te verilmiştir. Gruplar arası ve grup içi değişkenlerine göre, koruyucu katmanların yapışma direnci ve sertlik değerine etkisini belirlemek üzere yapılan varyans analizi sonuçları Tablo 4'te verilmiştir. Tablo 4'teki gruplar aras1 değişkenlerde, koruyucu katmanların yapışma direnci üzerindeki etkisi önemsiz, sertlik değerine etkisi ise 0,05 hata payı ile istatistiksel anlamda önemli bulunmuştur.

Koruyucu katmanların sertlik ortalama değerleri Duncan testi sonuçları Tablo 5'da verilmiştir. Tablo 5'ya göre en yüksek sertlik değerleri, $\mathrm{OHT}+\mathrm{SbV}$ (38) ve $\mathrm{SbV}$ (35) numunelerinde, en düşük sertlik değerleri ise $\mathrm{SbB} \quad$ (28.2) ve $\mathrm{OHT}+\mathrm{SbB} \quad$ (25.6) numunelerinde tespit edilmiştir. Bu sonuçlara göre, yağlı 1sıl işlemin vernik ve boya katman sertliğine olumsuz bir etki yapmadığ söylenebilir. Benzer şekilde, Petrič ve ark. (2007) yağlı 1sıl işlem gören odunlarda su bazlı koruyucu katman uygulamalarının olumlu olacağını, Jämsä ve ark. (2000) da ahşaptan iyi bir görüntü elde edilmesi istenildiğinde, ssıl işlemli odunda koruyucu katman uygulamalarının uygun olacağını belirtmişlerdir.

Tablo 3. Koruyucu katmanların yapışma direnci ve sertlik değerleri

\begin{tabular}{clcccc}
\hline Direnç çeşidi & Koruyucu katman çeşidi & Xmin & Xmax & Xort & v (\%) \\
\hline \multirow{2}{*}{$\begin{array}{c}\text { Yapışma } \\
\text { (Mpa) }\end{array}$} & OHT+SbV & 2.04 & 3.72 & 2.69 & 19.23 \\
\cline { 2 - 5 } & SbV & 2.18 & 3.75 & 2.92 & 18.28 \\
\cline { 2 - 5 } & OHT+SbB & 2.21 & 3.77 & 3.09 & 17.94 \\
\cline { 2 - 5 } & SbB & 2.29 & 3.83 & 3.20 & 15.68 \\
\hline $\begin{array}{c}\text { Sertlik } \\
\text { (Salınım) }\end{array}$ & OHT+SbV & 31 & 48 & 38.00 & 15.29 \\
\cline { 2 - 5 } & SbV & 31 & 43 & 35.00 & 10.26 \\
\hline & OHT+SbB & 23 & 28 & 25.60 & 5.59 \\
\hline & SbB & 25 & 34 & 28.20 & 10.41 \\
\hline
\end{tabular}

OHT: Yağlı 1sıl işlem, SbV: Su bazlı vernik, SbB: Su bazlı boya, v: Varyasyon katsayısı 
Tablo 4. Koruyucu katmanların yapışma direnci ve sertlik değerlerine ilişkin varyans analizi sonuçları

\begin{tabular}{|c|c|c|c|c|c|c|}
\hline $\begin{array}{l}\text { Direnç } \\
\text { Çeşidi }\end{array}$ & $\begin{array}{l}\text { Varyans } \\
\text { Kaynağı }\end{array}$ & $\begin{array}{c}\text { Serbestlik } \\
\text { Derecesi }\end{array}$ & $\begin{array}{c}\text { Kareler } \\
\text { Toplamı }\end{array}$ & $\begin{array}{c}\text { Kareler } \\
\text { Ortalaması }\end{array}$ & $\begin{array}{c}\text { F } \\
\text { Hesap }\end{array}$ & $\begin{array}{c}\text { Önem Düzeyi } \\
(\alpha=0.05)\end{array}$ \\
\hline \multirow{3}{*}{ Yapışma } & Gruplar aras1 & 3.00 & 1.50 & 0.50 & \multirow{3}{*}{1.80} & \multirow{3}{*}{$0.165^{\mathrm{ns}}$} \\
\hline & Grup içi & 36.00 & 9.99 & 0.28 & & \\
\hline & Toplam & 39.00 & 11.49 & & & \\
\hline \multirow{3}{*}{ Sertlik } & Gruplar aras1 & 3.00 & 1000.40 & 333.47 & \multirow{3}{*}{23.27} & \multirow{3}{*}{0.000} \\
\hline & Grup içi & 36.00 & 516.00 & 14.33 & & \\
\hline & Toplam & 39.00 & 1516.40 & & & \\
\hline
\end{tabular}

ns: önemsiz

Tablo 5. Koruyucu katmanların sertlik ortalama değerleri Duncan testi sonuçları

\begin{tabular}{lcc}
\hline Koruyucu Katman Çeşidi & $\overline{\mathbf{x}}$ (Salınım) & Homojen Gruplar* \\
\hline $\mathrm{OHT}+\mathrm{SbV}$ & 38 & $\mathrm{~A}$ \\
\hline $\mathrm{SbV}$ & 35 & $\mathrm{~A}$ \\
\hline $\mathrm{SbB}$ & 28.2 & $\mathrm{~B}$ \\
\hline $\mathrm{OHT}+\mathrm{SbB}$ & 25.6 & $\mathrm{~B}$ \\
\hline * $\mathrm{LSD}=3.42$ & &
\end{tabular}

\section{Sonuç ve Öneriler}

$\mathrm{Bu}$ çalışmada, bezir yağı ile isıl işlem görmüş sarıçam odununa uygulanan vernik ve boya katmanlarının, yapışma ve sertlik değeri bulguları tartışılmıştır. Buna göre, bezir yağı ile 1 sıl işlem uygulamasının vernik ve boya katmanlarının yapışma özelliklerine olumsuz yönde istatiksel olarak önemli bir etkisinin olmadığı tespit edilmiștir. Deney silindirleri ve numune yüzeyleri üzerindeki yapışma alanı incelendiğinde, çoğu numune yüzeylerinden koruyucu katman ile ağaç malzemenin birlikte koptuğu gözlemlenmiştir. $\mathrm{Bu}$ sebeple, vernik ve boyanın 1sıl işlem görmüş ağaç yüzeyine iyi bir yapışma sağlamış olduğu söylenebilir. $\mathrm{Bu}$ araştırmada, koruyucu katmanların yapışma dirençlerinin iyi çıkmasının sebebi Kimetsan firması tarafindan kullanılan yağ ile reaksiyona girerek yapışmayı güçlendiren ajanların kullanılması olarak düşünülmektedir.

Sonuç olarak, bezir yağlı 1 sıl işlem, sarıçam odununa uygulandığında, vernik ve boya katmanlarının yapışma ve sertlik performanslarına olumsuz bir etkide bulunmadığı tespit edilmiştir. FPInnovations ${ }^{\circledR} \quad$ (2008), yağlı 1 sil işlem görmüş Pinus contorta çamı odunlarına uygulanan su bazlı SuperNatural ${ }^{\circledR}$ verniğin performansinı olumlu bulması ile bu çalışmayı desteklemektedir. Dış ortamlarda, özellikle park ve bahçelerde kullanılacak ahşaptan üretilen eşyalara yağlı 1 sıl işlem yapılmas1 önerilebilir. Bundan sonra yapılacak çalışmalarda, yağlı 1 șl işlem görmüş odunlara yapılan vernik ve boya uygulamalarının, yaşlandırma etkisi altındaki renk değișimi, yapıșma ve sertlik gibi özelliklerinin araştırılarak bilim dünyasına katkı sağlanması faydalı olacaktır.

\section{Kaynaklar}

Anonim, 2015. Firma Güvenlik Bilgi Formu, Yeni Turan Bezir Yağ San. ve Tic. A.Ș., İstanbul. ASTM D 4366-95., Test Methods for Hardness of Organic Coatings by Pendulum Damping Tests. ASTM International, USA, 2002.

ASTM D-3023, Standard Practice for Determination of Resistance of Factory-Applied Coatings on Wood Products to Stains and Reagents. ASTM International, USA, 2011.

ASTM D-4541, Standard Test Method for Pull-Off Strength of Coatings Using Portable Adhesion Testers. ASTM International, USA, 2009.

Atar, M., Keskin, H., Kurt, R. 2003. Sarıçam odununda emprenye etme ve renk açma işleminin vernik katman sertliğine etkileri. KSÜ Fen ve Mühendislik Dergisi, 6(1), 85-96. 
Bazyar, B. 2012. Decay resistance and physical properties of oil heat treated aspen wood. BioResources, 7(1), 0696-0705.

Dubey, M.K., Pang, S., Walker, J. 2011. Effect of oil heating age on colour and dimensional stability of heat treated Pinus radiata. European Journal of Wood and Wood Products, 69 (2), 255-262.

Dubey, M.K., Pang, S., Walker, J. 2012. Changes in chemistry, color, dimensional stability and fungal resistance of Pinus radiata D. Don wood with oil heat-treatment, Holzforschung, 66 (1), 49-57.

FPInnovations ${ }^{\circledR}$ Forintek Division, Canada, 2008. Coatability of oil-thermal-treated post MPB Lodgepole pine sapwood.

Hill, C.A.S. 2006, Wood modification chemical thermal and other processes, John Wiley $\&$ Sons Pres.

Homan, W., Tjeerdsma, B., Beckers, E. Jorissen, A. 2000. Structural and other properties of modified wood. World conference on timber engineering. Whistler Resort, British Columbia, Canada July 31 - August 3, 2000.

Jämsä, S., Ahola, P., Viitaniemi, P. 2000. Long-term natural weathering of coated ThermoWood. Pigment \& Resin Technology, 29 (2), 68-74

Özkan, O.E. 2013. Isıl işlemle muamele edilmiş göknar odununun biyolojik, mekanik, fiziksel ve dış ortam dayanımı özellikleri. Yüksek Lisans Tezi, Kastamonu Üniversitesi Fen Bilimleri Enstitüsü, 95 s. Kastamonu.

Petrič, M., Knehtl, B., Krause, A., Militz, H., Pavlič, M., Pétrissans, M., Gérardin, P. 2007. Wettability of waterborne coatings on chemically and thermally modified pine wood. Journal of Coatings Technology and Research, 4 (2), 203206. DOI 10.1007/s11998-007-9023-2

Sidorova, E. 2008. Oil heat treatment of wood. Proceedings of the $4^{\text {th }}$ meeting of the Nordic Baltic Network in Wood Material Science \& Engineering, 13-14 November, Riga, Latvia.

Suttie, E., Thompson, J.H.R. 2001. Opportunites for UK Grown Timber: Wood Modification State of The Art Review. DTI Contruction Industry Directorate and Forestry Commission, Project Report Number 203-343.

Temiz, A., Terziev, N., Jacobsen, B., Eikenes, M. 2006. Weathering, water absorption, and durability of silicon, acetylated, and heat-treated wood. Journal of Applied Polymer Science, 102 (5), 4506-4513. DOI:10.1002/app.24878

Tomak, E.D., Y1ld1z, Ü.C. 2010. Odunun kimyasal modifikasyonu. III. Ulusal Karadeniz Ormancılık Kongresi 20-22 Mayıs 2010 Cilt: IV Sayfa: 1681-1690.
TS EN 351-1, Ahşap ve Ahşap Esasl Mamullerin Dayanıklılığı-Emprenye Edilmiş Masif Ahşap-Bölüm 1: Emprenye Maddesinin Nüfuz Derinliği ve Tutulma Miktarının Sinıflandirılması. T.S.E., Ankara 2010.

TS EN ISO 4624, Boyalar ve Vernikler Yapışmanın Tayini İçin Çekme Deneyi. T.S.E., Ankara 2006.

TS.2470, Odunda Fiziksel ve Mekaniksel Deneyler İçin Numune Alma Metotları ve Genel Özellikler, T.S.E., Ankara, 1976.

Yildiz, S., Yildiz, U.C., Tomak, E.D. 2011. The effects of natural weathering on the properties of heat treated alder wood. BioRes., 6 (3), 2504-2. 